\title{
IPCC SRES REVISITED: A RESPONSE ${ }^{1}$
}

\author{
Nebojsa Nakicenovic, Arnulf Grübler, Stuard Gaffin, Tae Tong Jung, \\ Tom Kram, Tsuneyuki Morita, Hugh Pitcher, Keywan Riahi, \\ Michael Schlesinger, P. R. Shukla, Detlef van Vuuren, Ged Davis, \\ Laurie Michaelis, Rob Swart and Nadja Victor
}

\section{ACKNOWLEDGEMENTS:}

We thank Vadim Chirkov, Erik Slentoe, and Jayant Sathaye for their assistance and comments.

\begin{abstract}
Mr. Castles and Mr. Henderson have criticized the Special Report on Emissions Scenarios (SRES) and other aspects of IPCC assessments. It is claimed that the methodology is "technically unsound" because market exchange rates (MER) are used instead of purchasing power parities (PPP) and that the scenarios themselves are flawed because the GDP growth in the developing regions is too high.
\end{abstract}

The response is:

- The IPCC SRES reviews existing literature, most of which is MER based, including that from the World Bank, IEA and USDoE.

- Scenarios of GDP growth are typically expressed as MER (the preferred measure for GDP growth, as opposed to PPP which is a preferred measure for assessing differences in economic welfare).

- IPCC scenarios did include PPP-based scenarios, which Mr. Castles and Mr. Henderson have conveniently ignored.

- Contrary to what Mr. Castles and Mr. Henderson claim, IPCC scenarios are consistent with historical data, including that from 1990 to 2000, and with the most recent near term (up to 2020) projections of other agencies.

- Long-term emissions are based on multiple, interdependent driving forces, and not just economic growth. Mr. Castles and Mr. Henderson need to look beyond GDP.

1 Views or opinions expressed herein are those of the authors and do not necessarily represent those of the Intergovernmental Panel on Climate Change or any other organization. Correspondence should be sent to Nebojsa Nakicenovic, IIASA, A2361 Laxenburg, Austria (email: naki@iiasa.ac.at).

The following lead authors of the Special Report on Emissions Scenarios did not have time to review and contribute to the rebuttal written by Nakicenovic et al. (this issue) due to an extremely short journal timetable. They wish to express their support for the general technical points made in the rebuttal and affirm the overall soundness of the SRES: Joergen Fenhann, Lynn Price, Steven J. Smith, Bart de Vries, Ernst Worrell and Alexander Roehrl 
- The IPCC scenarios provided information for only four world regions, and not for specific countries. Mr. Castles' and Mr. Henderson's critique is not of IPCC scenarios but of ongoing unpublished work in progress that is not part of SRES. We therefore show that Mr. Castles and Mr. Henderson have focused on constructing a "problem" that does not exist. SRES scenarios are sound and the IPCC has responded seriously and conscientiously.

We detail our response below in nine sections. After an introduction (Section 1), we outline the SRES methodology for measuring economic output (Section 2). Section 3 compares SRES to long-historical economic development and provides five responses to the critics. Section 4 addresses the issue of country-level economic projections even if not part of SRES. Sections 5, 6 and 7 validate the SRES scenarios by comparing them with recent trends for economic and $\mathrm{CO}_{2}$ emission growth, as well as more recent scenarios available in the literature. Section 8 refutes the argument that lower economic growth in developing countries would lower GHG emissions correspondingly. Section 9 concludes.

\section{INTRODUCTION}

Emissions scenarios are an important component of IPCC assessments. They are part of a long process and do not represent a one-time occurrence. The first set of three scenarios was developed in 1990 and was used as input to climate models. The second set was completed in 1992 and included a wider range of driving forces and emissions, the so-called IS92 set of six scenarios (Leggett et al., 1992). It was used very widely in the literature as baselines for other studies and in the IPCC assessments. In 1995, the IPCC evaluated the purpose and use of emissions scenarios (Alcamo et al., 1995). Based on the recommendations of this process, the terms of reference for new scenarios were approved and a writing team appointed in 1996 (SRES, 2000). In time, there is no doubt that the SRES scenarios themselves will need to be revised and updated or replaced by a new set. In this respect we concur with Mr. Henderson (document 2(2):6 in this issue) that the process and evaluation of scenarios should not only begin but that, as in the past, it needs to be a continuous effort that integrates new information and scientific findings as they become available. In fact, the Amsterdam meeting, 8-10 January 2003, to which Mr. Castles and Mr. Henderson were invited, was a part of this process. The question addressed here is different. It is whether the criticisms advanced by Mr. Castles and Mr. Henderson in this issue of Energy and Environment and elsewhere are warranted and whether the SRES scenarios are flawed and unsound as they assert.

Over the period of more than three years, the IPCC writing team developed a set of long-term emissions scenarios and documented them in a Special Report on Emissions Scenarios (SRES, 2000). The international and interdisciplinary writing team that assessed the emissions scenarios literature and developed the set of 40 emissions scenarios consisted of 53 Authors and 4 Review Editors. In addition to scientists, the interdisciplinary writing team also included experts from NGOs and the private sector. The work on the scenarios included an "open process" that invited modelling groups 
and individuals to contribute to the scenario development. Six leading modelling teams participated in formulating the scenarios that included systems-engineering as well as macro-economic models. As a part of the open process, the initial scenarios were posted on a website during the development process so that they could be evaluated by various stakeholders and the scientific community at large. More than 34,000 accesses were registered by April 1999 when the website was closed, resulting in numerous interactions and revisions of initial scenarios. The scenarios were extensively reviewed both by 89 experts and by governments prior to IPCC approval and publication in 2000. Based on these reviews, first the writing team and then the IPCC Working Group III plenary session in Katmandu, Nepal, March 2000, modified and subsequently approved the Special Report on Emissions Scenarios (SRES). It was published by Cambridge University Press (SRES, 2000) and is also available through the IPCC website (www.ipcc.ch). The underlying scenarios and the background materials have also been published in two special issues of scientific journals (Alcamo and Nakicenovic, 1998; and Nakicenovic, 2000) and many other publications in the peer-reviewed literature.

Over the past six months Mr. Castles and Mr. Henderson have criticized the Special Report on Emissions Scenarios (SRES, 2000) and other aspects of IPCC assessments. They have summarized their views in five separate documents in this issue of Energy and Environment, on many websites and elsewhere including a recent article in the Economist (18 February 2003). For example, the identical set of documents as published in this issue by Mr. Castles and Mr. Henderson is posted on the Lavoisier Group's website (http://www.lavoisier.com.au/). ${ }^{2}$ Addressing the issues raised in the five different documents by Mr. Castles and Mr. Henderson in this issue has resulted in some repetition in this rebuttal. We apologize to the reader for this but felt it necessary to clarify the situation one last time and to answer the assertions by Mr. Castles and Mr. Henderson of non-responsiveness by the IPCC to their comments. Although the IPCC normally only responds to comments within the context of the document review process, which was ample, and not to subsequent comments, this courtesy was extended to Mr. Castles and Mr. Henderson. This included inviting their participation at the IPCC meeting in January in Amsterdam, where discussions with various SRES authors were held. We therefore believe that sufficient credence was given to the critiques of Mr. Castles and Mr. Henderson as reproduced in this journal and that their subsequent actions are outside the normal spirit of dialogue. In fact, it is they that have not responded to the discussions and dialogues afforded them, but have used this opportunity to merely repeat their points of view.

The main thrust of the critique is two-fold, first that the methodology used to

2 In his introductory remarks at the Amsterdam meeting, 8-10 January 2003, Mr. Castles asserted that he is "not affiliated with any... organization involved in climate change matters" (document 2(1):1 in this issue) whereas he is a member of the Lavoisier Group (http://www.lavoisier.com.au/, see president's statement) that deals almost exclusively with climate change matters. This begs the question whether other statements and criticisms advanced in his contribution to this issue of Energy and Environment are equally misleading. We believe that this is the case with many of the assertions that the SRES scenarios are "unsound". 
develop scenarios is flawed and second that the scenarios themselves are flawed because the assumptions behind them are "technically unsound" (http://www.lavoisier.com.au/ and document 2(1) in this issue).

The methodology critique focuses on the measurement of economic product in the scenarios. It is claimed that market exchange rates (MER) are used instead of purchasing power parities (PPP), the exclusively preferred method by Mr. Castles. In contrast to most scenarios in the literature, SRES does report both MER and PPP for all four scenario families. Six integrated modelling frameworks were used in SRES to develop 40 scenarios that are grouped in the four scenario families that share common assumptions about economic development, population growth and final energy requirements, among other things. One of the six models is parameterized equally for PPP so that all four economic development paths for the four scenario families are reported in SRES both in terms of PPP and MER. Therefore, the criticism is misplaced and misleading and this has been pointed out during the joint meetings of some SRES authors with Mr. Castles and Mr. Henderson in Amsterdam, 8-10 January, 2003.

The response to the criticisms about "unsound" scenario assumptions is phenomenological: SRES driving forces and resulting emissions are compared with historical developments, both long-term as in the SRES report and with those of the last decade, and recent scenarios in the literature. The comparison with historical development is extensive in Chapters 3 and 4 of the SRES report itself, Chapter 3 focuses almost exclusively on the long-term historical developments that are relevant for emissions scenarios. Here we comment only on the comparison of historical economic growth experiences both in MER and PPP with the SRES development paths as this is one of the main criticisms advanced in this issue. We focus on showing that the scenarios are consistent both with long-term as well as recent (the last decade) historical developments, again both in terms of PPP and MER.

This is important because most of the models were calibrated for the year 1990 at the time of the completion of the 40 scenarios. In contrast to the statement by Mr. Henderson (document 3(2):1 in this issue) that "SRES could probably have drawn on the IMF data that were available by April 1999," the calibration of the base-year in the six integrated assessment models requires the full set of data (such as the input-output tables, capital vintage structures, detailed energy balances and land-use patterns) and enormous resources. This is one of the reasons why harmonization of scenarios was conducted (SRES, 2000). The objective was to reflect the developments of that decade in the scenarios. As a result, in virtually all the cases of now historical development through 2000 we have studied, the SRES assumptions are consistent with historical development and have stood the test of time.

This could be considered surprising as the purpose of the scenarios was to provide a range of possible longer-term developments through to 2100 and not to capture the short-term developments of the present decade. Finally, we compare economic shorter-term development in the SRES scenarios with those published in the meantime by the World Bank (2003a) and the U.S. Energy Information Agency (EIA, 2002). Here again, the development across SRES scenarios captures well the range of these more recent studies, both of which express economic development in terms of MER and not PPP. All other scenario literature that has emerged since the publication of 
SRES is based on MER as well, e.g. World Bank (2003a), USDoE (2002, 2003), etc. All government reports to UNFCCC also give their respective GDP in terms of MER (http://unfecc.int/) and not in PPP. This strongly suggests that measuring economic output in terms of MER is a widely accepted methodology and that the SRES approach of using both PPP and MER as alternative measures of economic development was innovative especially as it was based on exceedingly sparse literature of economic scenarios measured at PPP.

\section{SRES METHODOLOGY FOR MEASURING ECONOMIC PRODUCT}

Mr. Castles raises a number of concerns about the methodology used to develop SRES scenarios. The most fundamental objection is the assertion that SRES used a supposedly flawed methodology of measuring economic development in terms of MER rather than in terms of PPP. This is simply not correct as far as the SRES report is concerned. The process of formulating SRES scenarios involved measuring future economic development in terms of GDP both in terms of MER and PPP. On 8-10 January 2003, Mr. Castles was informed explicitly about this fact. Both measurements of GDP are provided in the underlying report and in particular in Appendix VII for all MESSAGE scenarios (see also in SRES, 2000: Figure 3-1; Section 3.3.1, Box 3-1, Figure 3-12, and Table 4-19). The writing team decided not to report both measures of GDP throughout the SRES report in order not to generate confusion about growth rates and other scenario indicators that include GDP especially in comparison with the literature that almost exclusively reports GDP in MER, and which the SRES writing team had the mandate to review.

Figure 1 shows the per capita GDP development across the four SRES scenario families in both PPP and MER. The data are taken directly from SRES (2000: 401-405, 416-420, 431-435, 446-450, 481-485, 516-520, 526-535 and 561-565) report. The disparities between PPP and MER measures are very high especially for the developing regions of the world. Figure 1 shows that these disparities decrease with development so that they are significantly lower by mid century and slowly converge toward the end of the century. This is consistent both with the economic theory (Voeller, 1981) and with inter-country comparisons (de la Esconsura, 2000; Kravis et al., 1978). The insert in the figure highlights these differences between the two measures during the next three decades across the scenarios.

The authors do concur with Mr. Castles that PPP is a better measure for purposes of (static) comparisons of economic welfare (income and consumption) across different world regions and countries. This was the primary motivation in developing and reporting PPP measures also for the SRES scenarios. However, the authors sharply disagree with Mr. Castles and Mr. Henderson that PPP would be a preferred measure for developing long-term GDP growth scenarios. This would also be inconsistent with the vast majority of the scenario literature, the state of art of models available for economic projections, as well as the state of art of models available to develop long-term emissions scenarios. It should be noted that while economic development in all four scenario families is defined in terms of both MER and PPP, only one of the six integrated modelling frameworks used to quantify SRES scenarios is calibrated for both GDP measures. This is clearly indicated in the SRES report (e.g., 


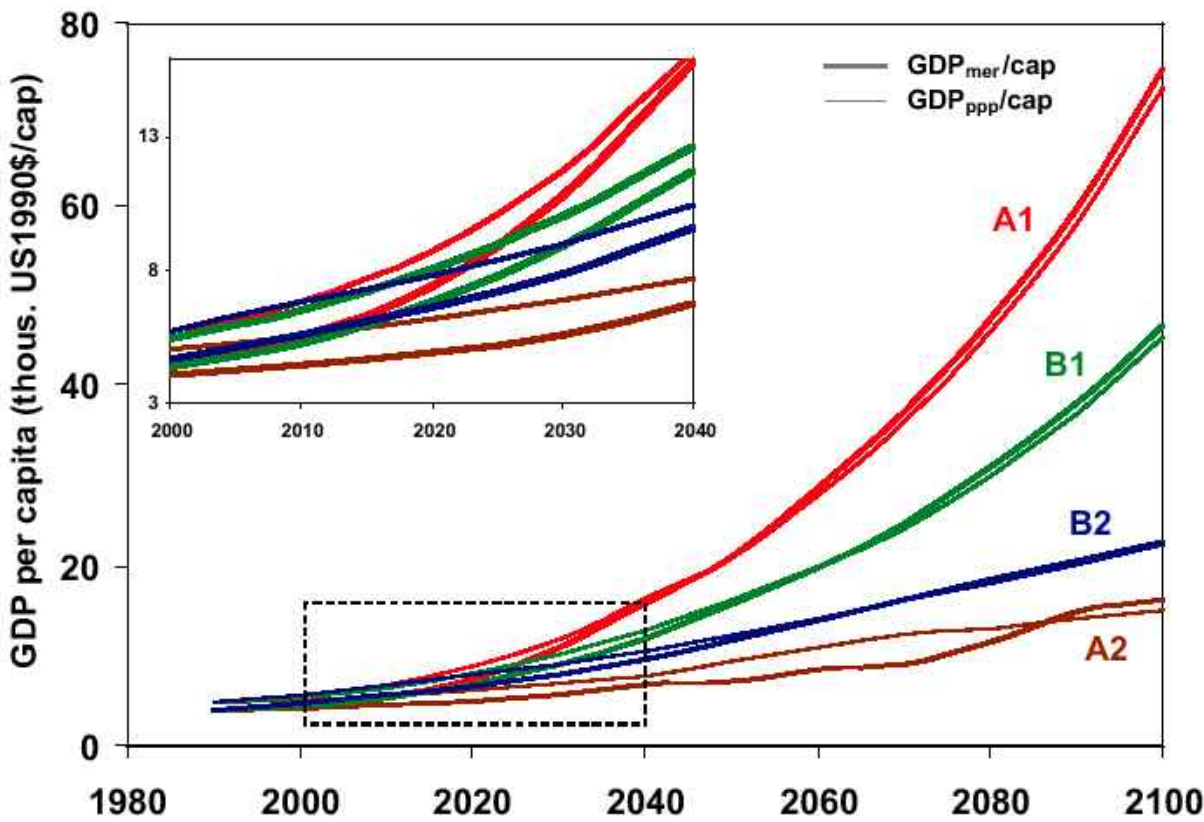

Figure 1: Per capita GDP development across the four SRES scenario families in both PPP and MER (based on SRES scenarios calculated with the MESSAGE model), in thousand 1990 US dollars per capita (Source: SRES, 2000).

see p. 115 where it is stated that PPP development paths are calculated by one of the six modelling approaches, namely by MESSAGE). The authors of this contribution are not aware of any other integrated assessment model that is calibrated in terms of PPP. In fact, we are not aware of any long-term economic model that is calibrated in $\mathrm{PPP}^{3}$. According to Nordhaus and Boyer (2000: 43) there are three reasons for using MER in economic models rather than PPP: First, historical output data at MER are more readily available than at PPP exchange rates; second, in the context of optimizing regional consumption paths, internal prices should be used rather than the world average price level; and third, international trade in energy and possibly carbon (in the future) take place at MER. Consider the case of any developing country: for the import of a barrel of oil, or a ton of grain, the market exchange rate determines how many units of local currency need to be paid for the prices of commodities and products traded internationally. Arguing that PPP would provide a more appropriate exchange rate could of course reduce the price to be paid in local currencies for a barrel of oil or a ton of grain, but evidently at the expense of not being able to perform

3 This also includes the GREEN model originally developed at the OECD. This model is not calibrated in terms of PPP despite the fact that Mr. Henderson worked at OECD. The question is why Mr. Henderson was not able to convince his colleagues at the OECD to use the "sound" methodology of PPP he is recommending to the IPCC. 
the market transaction at all! Mr. Castles and Mr. Henderson tend to forget in their critique that the main appeal of market exchange rates is that they can actually be observed in market transactions. In contrast, PPP need to be estimated by statistical offices and international organizations. Equally, only MER assure consistency in models incorporating international trade.

The above mentioned methodological and measurement issues explain the virtual lack of economic scenarios measured in PPP in the literature. The SRES team developed a database that includes more than 500 emissions scenarios published in the literature. This was necessary in order to determine the range of emissions and driving forces in the published scenarios. Virtually all of these scenarios report economic development in terms of MER, which continues to be state-of-the art practice of all organizations preparing long-term economic, energy, or emissions scenarios, including the World Bank, the International Energy Agency, and the US Department of Energy. The few exceptions of studies (next to SRES) that report PPP include: Energy for Tomorrow's World (WEC, 1993), Global Energy Perspectives (Nakicenovic et al., 1998), and the recent scenarios of the Global Scenario Group (Raskin et al., 2002; Kemp-Benedict et al., 2002) as well as Maddison's single projection to the year 2015 (Maddison, 2002).

Thus, this misplaced criticism ignores the fact that the economic models used to develop long-term development paths in the scenarios are generally calibrated in MER so that MER has to be used as well. To do otherwise would be to ignore virtually all of the underlying literature, models and scenarios, e.g., World Bank (2003a), USDoE (2002), IEA (2002a). Mr. Castles claims that using MER in the context of long-term scenarios is "unprofessional use of statistics to make exaggerated statements" (document 2(1):3 in this issue), whereas in fact his criticism is at least in part uninformed, misleading and thus unprofessional. One might ask therefore how it is possible that Mr. Castles continues to claim that SRES used MER exclusively and has not recognized the fact that all four GDP development paths are also given in PPP in the SRES report. This is especially curious considering the extensive discussions held between Mr. Castles and SRES authors at the 8-10 January 2003 meeting in Amsterdam during which he was explicitly and repeatedly shown the exact pages in the SRES Report where the PPP development paths are given (SRES, 2000: 401-405, 416-420, 431-435, 446-450, 481-485, 516-520, 526-535 and 561-565). Therefore, this perhaps most important aspect of the criticism has to be dismissed, namely that flawed methodology has been used to measure GDP. It is simply counterfactual because it is documented that PPP was used in SRES as well as MER.

We challenge Mr. Castles either to develop himself PPP-based long-term scenario(s) or identify such development paths from the literature that would show the supposed shortcomings of the four SRES PPP scenario quantifications.

The per capita GDP developments and growth rates clearly show that Mr. Castles' assertions about exaggerated growth in SRES scenarios are not correct when expressed in terms of PPP (see also his letter to Dr. Pachauri dated 6 August 2002, posted on Lavoisier Group http://www.lavoisier.com.au/). For example, the Table in the Appendix hereto clearly shows that income per capita differences are 8.6 to 1 (between ASIA and OECD90) in 1990 when measured in PPP and 38.2 to 1 when 
measured in terms of MER (SRES, 2000: 197). Both measures are correct. Highlighting the difference between them as an error is again curious, as it does not have a substantive effect on the results such as the emissions paths. The ratio of 8.6 to 1 corresponds well to Mr. Castles' assertion that it should be 10 to 1 for the two regions when "properly measured".

The same is the case in characterizing future changes in per capita incomes. For example, in A1 scenarios per capita income in ASIA increases by a factor of 143.8 between 1990 and 2100 when measured in MER (as Mr. Castles correctly observes), but only by a factor of 37.8 when measured in terms of PPP. This corresponds to an annual average growth rate of 3.3 percent, which is well in line with historical experience. The equivalent numbers for the B1 scenario are a factor per capita income growth of 71.6 in terms of MER (as he correctly observes) and a factor of 18.8 in terms of PPP with a corresponding annual growth rate of 2.7 percent. This illustrates that, contrary to the claims of Mr. Castles and Mr. Henderson, the SRES writing team was very well aware of the implications of using PPP as an alternative measure and that far from being "technically unsound", the SRES report describes the economic development scenarios comprehensively and multidimensionally.

\section{SRES AND LONG-HISTORICAL ECONOMIC DEVELOPMENT}

One of the most pervasive complaints, especially in Mr. Castles' contributions to this issue, concerns the economic growth in developing regions of the world. The claim is made repeatedly that SRES scenarios overstate what Mr. Castles and Mr. Henderson consider to be appropriate development trajectories. Before addressing this critique on the supposedly "too high" economic growth assumptions for developing countries in the SRES scenarios it is useful to recall both the very concept of scenarios as well as the terms of reference under which the SRES scenarios were developed.

The concept of scenarios (emphasis on plural!) owes its origins to military contingency planning and more recently various strategic planning exercises. Consequently, the objective is not to "predict" what will, but rather what could happen under a sequence of (sometimes extreme) events. Scenarios are therefore mind experiments to assess possible consequences of a series of "what if... then" developments. Appropriate evaluation criteria are internal consistency, reproducibility and plausibility of scenario "logic" rather than "likelihood" or conformity with a priori expectations of "most likely" chain of events under any particular temporal (e.g., before or after the "Asian financial crisis") or geographical (e.g., OECD) bias. Scenarios are therefore neither predictions, nor forecasts. ${ }^{4}$ Consequently, the SRES writing team has explicitly refrained from assigning (inherently subjective) likelihoods or "probabilities" of occurrence to the scenarios and has repeatedly cautioned against the interpretation of any scenario as "most likely" or as "business as usual" in the traditional deterministic sense of a "forecast" or "prediction" (even if

4 This is clearly stated in SRES (2000), but unfortunately the publisher mistakenly used the word "prediction" in the short text on the back of the jacket as Mr. Castles was quick to notice (document 2(1):1 in this issue) that we as authors unfortunately caught too late to correct. 
these terms continue to be used in the popular media). The appropriate use of scenarios refrains from "picking" any particular chain of events, but rather focuses on how a range of scenarios describes the most important uncertainties at stake.

Two documents constitute the terms of reference set forth by the IPCC and the SRES writing team at the onset of the SRES process. The IPCC terms of references (SRES, 2000:324-325) called for the development of a range of "non intervention" scenarios, i.e., scenarios that assume "no additional climate policy initiatives" (as of 1996, i.e., excluding, for example, all possible outcomes of the Kyoto Protocol), reflecting uncertainty through a review of the underlying scenario literature and calling for an "open" process under methodological (read: modelling) pluralism in the development of the new IPCC scenarios.

The SRES writing team also agreed right from the beginning to consider seriously the results of a scientific evaluation of the previous IPCC IS92 emission scenarios in this new emissions scenario assessment. In that evaluation a number of recommendations were put forward for the development of new IPCC emission scenarios (Alcamo et al., 1995:297), in particular, to develop scenarios that "examine different trends in technological change", as well as scenarios exploring "a variety of economic development pathways, for example, a closing of the income gap between industrialised and developing regions".

These terms of reference explain why certain future emission pathways, like very low emission futures resulting from climate policy initiatives were not explored in SRES. (They were reported in the Third Assessment Report, cf. Metz et al. (2001), where a range of climate stabilization scenarios based on the "non-intervention" SRES scenarios were examined in detail.) The SRES terms of reference also explain why both in terms of scenario metric (e.g., in measuring economic output based on market exchange rates MER or purchasing power parities PPP), as well as in terms of scenario variants examined (e.g., scenarios of income gap close versus those of non-closure), the number of scenarios is not equally spaced within the set of 40 SRES scenarios that together cover the most important uncertainties in terms of demographics, economics, technology and resulting GHG emissions.

The fact that 17 out of the 40 SRES scenarios explore alternative technological development pathways under a high growth (and corresponding high R\&D and high capital turnover) scenario family A1 does not constitute a statement that such scenarios should be considered as more likely than others with a less dynamic technological and economic development outlook, nor that a similar large number of technological "bifurcation" scenarios would not be possible in any of the other three scenario families. Reflecting the aim of exploring alternative economic development pathways that lead to a conditional and gradual closing of the relative "North-South" income gap, two of the four SRES scenario families (A1 and B1) consider this possibility (but each following different strategies towards that end), whereas two others adopt a more cautious (B2) or even pessimistic (A2) perspective where current income gap disparities persist throughout the century. Again this does not constitute a statement with respect to likelihood or desirability of such scenarios on behalf of the SRES writing team, but simply reflects principles of scenario parsimony and economy in view of the terms of reference underlying the scenario exercise. 
Our response to Mr. Castles and Mr. Henderson on this topic focuses on five aspects.

\subsection{The fallacy of selective quotation}

First, their critique suffers from a serious defect of selective (biased) quotation of only a limited number of SRES scenarios (i.e., only the two "income closing" scenario families A1 and B1 are discussed). Equally, their criticisms almost exclusively focus on only two out of the 40 SRES scenarios (in particular, the two low emission scenarios B1-IMAGE and B1T-MESSAGE), whilst deliberately ignoring all other scenarios that explore alternative developments. It is not surprising that in a scenario exercise spanning such a wide range of possible developments there will always be disagreement on the plausibility or desirability of any particular scenario, particularly by those that were designed to explore the upper or lower bounds of salient scenario driving forces, be it population or economic growth, technology, or land-use changes.

Mr. Castles and Mr. Henderson obviously consider scenarios of a long-term closure of the North-South income gap highly unlikely, and many (including a larger part of the SRES authors) would agree with them. But does this make it illegitimate to explore in a "what if... then" scenario exercise the implications in terms of GHG emissions if indeed such development were to take place, especially in this case where previous IPCC scenarios were identified as having insufficiently explored this possibility? The answer is obviously that such scenarios need to be considered especially in the context of exploring the full range of future scenarios. The special value of the criticized SRES A1 and B1 scenarios resides precisely in the insight that such an income gap closure might not necessarily be associated with extremely high GHG emissions, but could also unfold even in the absence of climate policies with comparatively low emissions (as for instance explored in the technologically optimistic A1T and B1T scenarios).

As mentioned, other SRES scenarios adopt a more cautious (B2) or even pessimistic (A2) perspective on economic growth in the developing world and these scenarios are systematically ignored by Mr. Castles and Mr. Henderson. It is also entirely tautological to criticize the high growth scenarios in reference to the median of the scenario literature as done by Mr. Castles (document in this issue 3(1):4-5) with reference to the B1T-MESSAGE scenario or in comparison with historical experience (as done in his letter to the IPCC chair Dr. Pachauri), as such "high growth" scenarios by definition have to explore a scenario range that significantly lies above those explored by "middle of the ground" scenarios in the literature or that could be obtained by simply extrapolating historical trends into the future. In short, we certainly agree with $\mathrm{Mr}$. Castles and Mr. Henderson that the economic growth rates described in the SRES scenarios A1 and B1 for the developing countries are high and challenging, but they are so purposefully and legitimately in order to explore the uncertainties of the future.

\subsection{Comparing apples and oranges}

Second, in their critique Mr. Castles and Mr. Henderson systematically confuse MER and PPP GDP growth measures as reported in SRES and elsewhere, both in terms of comparing the scenarios to each other as well as in comparing the scenarios to both 
the historical and the prospective (scenario) literature. In short, they systematically construct a case out of comparing apples and oranges. For instance, throughout their critique an inappropriate comparison is made between the historical growth rates reported in the formidable statistical work of Angus Maddison, that reports GDP in PPP, with the MER growth rates reported in the SRES report, whereas a valid comparison would have considered the SRES PPP scenarios instead. Likewise, in his critique of the MESSAGE scenarios, Mr. Henderson (document in this issue 3(2):8) wonders why the 1990 to 2000 GDP growth varies between 20.6 and 35.4 percent when compared to the IMF projections of 36.5 percent, simply ignoring that the former (lower) number refers to PPP, while the latter (higher) number refers to MER and is in perfectly good agreement with the comparable IMF numbers quoted.

\subsection{SRES and the lessons from history}

Third, a repeated claim by Mr. Castles and Mr. Henderson is that the GDP growth rates for developing countries are outside the historical envelope and thus are "unrealistic" and invalid. In contrast, SRES growth rates cover the range of historical experiences for both GDP measures, PPP and MER, though the high-end scenarios of course describe developments for entire world regions, including the developing world, whereas long-term historical data exist mostly for individual OECD countries. Table 1a compares historical PPP growth rates for the past 100 years $^{5}$ with those for the four SRES world regions across the scenarios. The highest sustained historical growth rate

Table 1a. Historical GDP growth expressed at PPP (in constant \$1980) for the past 100 years and for the four SRES world regions across the scenarios

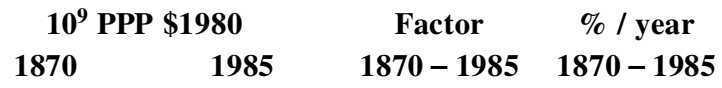

Historical GDP PPP growth

\begin{tabular}{lrrrr} 
UK & 59.0 & 510.9 & 8.7 & 1.9 \\
USA & 61.7 & 2947.1 & 47.8 & 3.4 \\
Canada & 4.9 & 306.8 & 62.1 & 3.7 \\
Japan & 17.2 & 1202.2 & 69.8 & 3.8 \\
\hline
\end{tabular}

SRES range (B2,B1,A1-MESSAGE)

OECD90

$\begin{array}{cc}\mathbf{1 9 9 0 - 2 1 0 0} & \mathbf{1 9 9 0 - 2 1 0 0} \\ 3.6-7.6 & 1.2-1.9 \\ 6.2-13.2 & 1.7-2.4 \\ 18.9-39.1 & 2.7-3.4 \\ 17.1-43.7 & 2.6-3.5\end{array}$

Sources: Kausel, 1985, SRES, 2000.

5 In order to follow the recommendation of Mr. Castles and Mr. Henderson to draw much more on expertise residing in national statistics offices, we drew here on the historical studies of Prof. Kausel, former deputy head of the Austrian Statistical office. 
was experienced in Japan and Canada with 3.8 and 3.7 percent per year, respectively. The highest growth rates for the next hundred years in SRES are in the developing regions of ALM and ASIA with up to 3.5 and 3.4 percent per year. Thus, the values are squarely within the historical experience.

Table $1 \mathrm{~b}$ gives a similar comparison for MER growth rates for the last 40 years compared with developments in two 40-year periods across the scenarios from 1990 to 2030 and 2030 to 2070. The highest sustained historical growth rates were experienced by Korea and Japan followed by Mexico with 7.6, 5.1 and 4.7 percent per year, respectively. Again, the SRES scenarios fall well within that range with the highest growth rates of 7.4 percent per year for the ASIA region between 1990 and 2030 and with at most 4.0 percent per year in the ALM region between 2030 and 2070. These examples clearly show that the assertion to the contrary by Mr. Castles is not correct.

The SRES growth rates are generally higher in the developing regions than in the more developed ones. This is also consistent with historical experience. By and large, growth rates are lower for economies at the technological and productivity frontier, compared to those approaching it (SRES, 2000: 116). This is also illustrated by Table 3-2 in SRES (2000: 117) with historical experience between 1870 and 1992 for major world regions and Table 4-7 in SRES (2000: 196) with historical experience between 1950 and 1990 for the four world regions (not reproduced here).

Table 1b. Historical GDP growth expressed at MER (in constant \$1995) for the past 40 years and for the four SRES world regions across the scenarios

$\begin{array}{cccc}10^{9} & \text { MER } \$ 1995 & \text { Factor } & \% / \text { year } \\ 1960 & 2000 & 1960-2000 & 1960-2000\end{array}$

Historical GDP MER growth

\begin{tabular}{lrrrr} 
Japan & 790.2 & 5687.6 & 7.2 & 5.1 \\
Korea & 33.1 & 620.4 & 18.7 & 7.6 \\
Merico & 60.6 & 372.9 & 6.2 & 4.7 \\
UK & 497.9 & 1294.4 & 2.6 & 2.4 \\
USA & 2376.8 & 9008.5 & 3.8 & 3.4 \\
World & 7882.4 & 34105.5 & 4.3 & 3.7 \\
\hline
\end{tabular}

SRES range (B2-A1 Markers)

$\%$ / year

1990-2030 2030-2070

OECD90

$1.8-2.1 \quad 0.7-1.8$

REF

$2.3-4.0 \quad 3.3-3.4$

ASIA

$6.7-7.4 \quad 2.8-3.8$

ALM

$3.9-6.0 \quad 3.9-4.0$

World

$3.3-3.7 \quad 1.9-3.1$ 


\subsection{Embracing uncertainty as reflected in the underlying literature, but refuting historical determinism}

Fourth, the critique is unfounded when the SRES scenarios are compared appropriately (either in MER or PPP) with the underlying scenario literature. This, in fact, is the only "observable space" of the future against which any scenario of the unknown can be meaningfully compared. Neither statistics covering the present nor the past are sufficient for such an exercise.

The SRES scenarios do indeed span the uncertainty range as reflected in the underlying scenario literature. This is illustrated in Figure 2 where the range of global GDP MER SRES scenarios is shown in comparison with the available literature also using this measure. ${ }^{6}$

The SRES scenarios of high economic growth and income gap closure are in the range of other comparable scenarios. They are high, even very high by design, but not

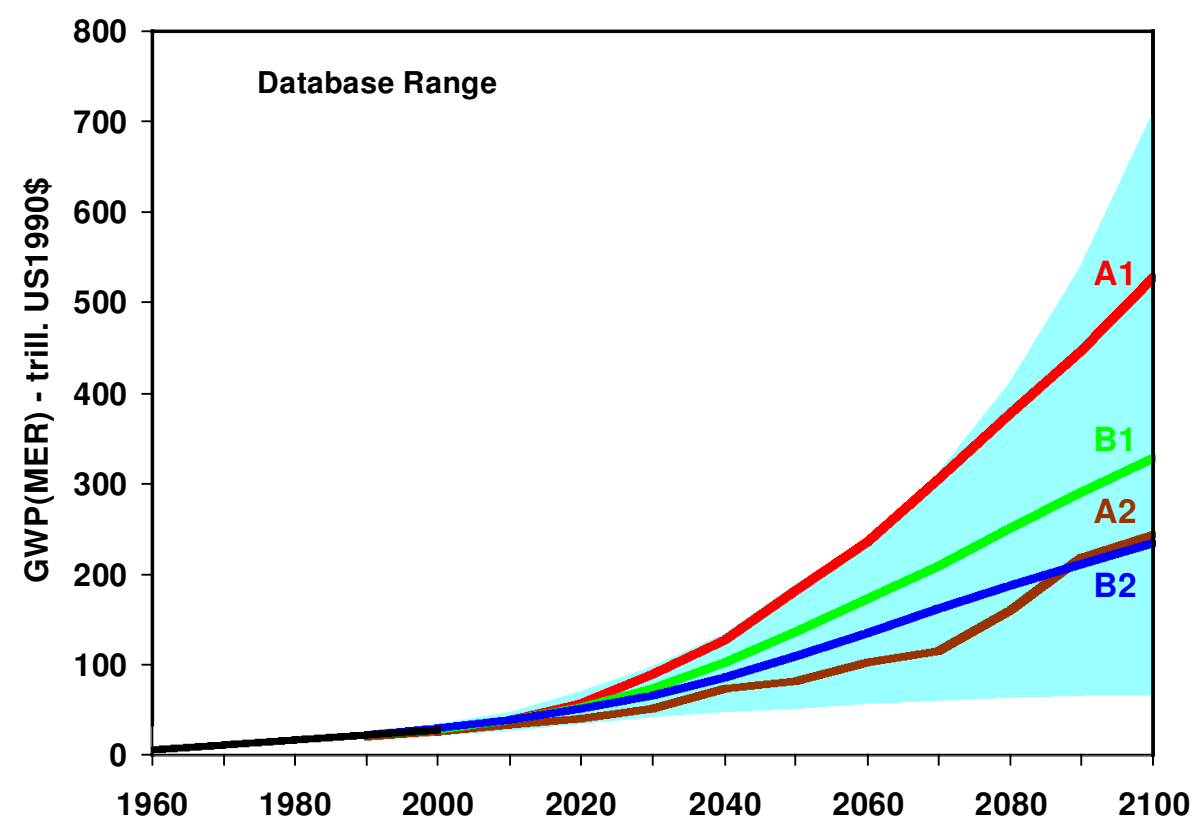

Figure 2. Scenarios of GDP growth expressed at MER (the preferred measure for GDP growth, as opposed to PPP which is a preferred measure for assessing differences in economic welfare), indexed to $1990=1$. Shown are the GDP growth paths of the four SRES marker scenarios compared to the statistics derived from analyzing close to 200 scenarios available in the literature. Source: Based on SRES (2000) and Nakicenovic et al. (1998).

6 As only statistics on global GDP scenarios are available in the published literature, our discussion focuses on global GDP scenarios. Providing similar systematic literature assessments at the regional level remains an important research task. 
higher than comparable scenarios existing in the literature. Other SRES economic growth scenarios are low, but again not lower than in comparable scenarios available. If indeed the SRES scenarios were "too high" with respect to economic growth in the developing countries, the resulting global scenarios would not be compatible with the scenario literature, simply because over such a long time horizon, global GDP growth is dominated by the growth of developing economies rather than that of already mature ones.

Scenarios may also be higher or lower than historical analogs quoted by both Mr. Castles and Mr. Henderson and in the SRES report, but this - contrary to the critics reflects rather the virtue of exploring future uncertainties via a scenario range rather than resorting to an inappropriate historical determinism. We cannot agree with $\mathrm{Mr}$. Castles and Mr. Henderson that the future can be determined by simply looking at the past. This does not diminish the importance of historical statistics and the valuable insights they provide, but simply states that not all futures might be derivable as simple extrapolations of past trends. After all, the 20th century was characterized by very different conditions in terms of geopolitics (colonialism), trade (deterioration of terms of trade for all major export commodities from developing countries), available technologies and human capital (education) for the developing world than postulated for the 21 st century in the high growth SRES scenarios. From this perspective, it would be a serious deficiency of the SRES scenarios if they could not describe in some scenarios a world in which the development aspirations of the "South" are to a large degree fulfilled. An important conclusion from the SRES scenarios is that, even assuming such a benign state of future affairs, it will take up to a century before present income inequalities (a ratio of four to one in PPP terms between the developed and developing regions as reported in SRES) are substantially reduced at the global scale and that there are alternative pathways in terms of the demand for materials, energy, and agricultural products, leading to a wide range of GHG emissions in pursuing such a scenario. Despite all the variation, the gap is however never closed entirely, even in scenarios with the highest growth.

\subsection{Geographical bias and the social construction of "possible" futures}

Because the future is unknown, there is no way of determining what constitutes a "too high" scenario with respect to income growth in developing countries. Mr. Castles and Mr. Henderson are apparently shocked by scenarios that imagine developing countries "incomes [growing] to far higher levels than the present OECD average" (Letter of Mr. Castles to the IPCC chair Dr. Pachauri, document in this issue (1(1):2). We are sure they would have been equally shocked 100 years ago about economic projections in which numerous "suspect" countries of economic "have-nots" would surpass the income level of the (then) dominant economic power (the USA). And yet, that is precisely what has happened. ${ }^{7}$ In 1900 the US per capita income level was around 4000 (constant 1990 international) dollars. By 1998, that level was surpassed by close to 40 countries, including developing economies such as Argentina, Brazil, Chile,

7 Based on Maddison (2001), a reference often quoted by Mr. Castles and Mr. Henderson. 
Columbia, Mexico, Thailand, Uruguay, and Venezuela, among others. More than 10 countries that qualified as "developing countries" in 1900 (having a per capita income below the world average) have today incomes above the ones enjoyed by the affluent US population in 1900. These "have nots" (from the perspective of the year 1900 and not already mentioned above) include: Bulgaria, Greece, Japan, South Korea, Taiwan, Turkey, and Yugoslavia. Present day Japanese income has grown to a level which is five times higher than the per capita income of the richest economy in the world some 100 years ago. So, who is to declare ex cathedra that similar broad based economic "success stories" are infeasible?

In essence, we interpret the critique of Mr. Castles and Mr. Henderson as reflecting an inappropriate "Northern" geographical bias and as an attempt to socially construct, or rather constrain our collective visions of "thinkable" futures. Even if Mr. Castles and Mr. Henderson do not consider scenarios of conditional relative income gap closure likely or acceptable to them, they should not attempt to censor alternative views of the future in which the developing world, unlike in recent history, is not lagging perennially further and further behind the OECD countries.

\section{SRES AND "DOWN-SCALING" TO COUNTRY LEVELS}

SRES scenarios were developed by the six integrated modelling frameworks for four world regions and not for individual countries. All of the scenarios, their driving forces and the resulting emissions are given for these four regions only. Thus, the whole discussion by Mr. Castles about "puzzling" developments in individual countries (document 3(1):1-4 in this issue) is not based on any of the SRES scenarios. This has to be stated categorically. The phrasing in their documents on this issue and especially in various media interviews given by Mr. Castles and Mr. Henderson and passages on numerous websites are all ambiguous to the degree that they imply that SRES gives country-level scenarios (e.g., http://www.abc.net.au/pm/s786179.htm, http://www.kuro5hin.org/print/2003/2/17/15110/5194).

The regional disaggregations of the six models are given in Table IV-I, SRES (2000: 338). The only regions that comprise single countries in some of the six models are: the US, Japan, Canada, China, Korea, Indonesia, Thailand and India. Because some other models do not include any single countries in their regional disaggregations, all of the scenarios are reported in SRES at the level of four world regions only.

Mr. Castles and Mr. Henderson had the benefit of participation in the IPCC scientific meeting in Amsterdam, 8-10 January 2003, where extensive discussions and a number of presentations dealt with one of the most challenging issues connected with global change in general, namely how to "down-scale" global phenomena to place-specific events. This is an unresolved problem, yet many of the crucial aspects related to global change occur at place-specific resolutions only. A number of very simple, initial methods to down-scale SRES and other scenarios were presented in Amsterdam, and the simplest one, namely the linear downscaling of some driving forces and emissions from the SRES four world regions down to country level was also posted on a web site quoted by Mr. Castles (document 3(1):1-4 in this issue). The website gives extensive caveats and descriptions of the shortcomings of this initial 
downscaling. It is also clearly stated that this is not IPCC approved work. These passages are not quoted by Mr. Castles.

Subsequently, due to the controversy that this has engendered since January 2003, the IPCC Task Group on Climate Impacts Assessment (TGCIA) has revisited the decision to provide this informal link and has decided to remove it from the page accessible through the IPCC Data Distribution Center (DDC). It is up to CIESIN, as an independent research organization, whether to make the information available through their own page. The IPCC TGCIA will discuss at its next meeting whether/how to handle provision of such information in the future. One option will be to maintain a reference list of related articles in the literature on the topic, which would include both ideas of how to do this sort of downscaling as well as comments on the approaches suggested. Again, this would be clearly described as non-IPCC approved work. It is the view of the authors of this article that Mr. Castles and Mr. Henderson owe such suggestions to the wider research community because their misplaced criticism of the work in progress in a public arena has led to the decisions by the IPCC to discontinue this service to the research community.

\section{SRES AND ECONOMIC DEVELOPMENT DURING THE LAST DECADE}

SRES went into review in 1999 with most of modelling work completed well before

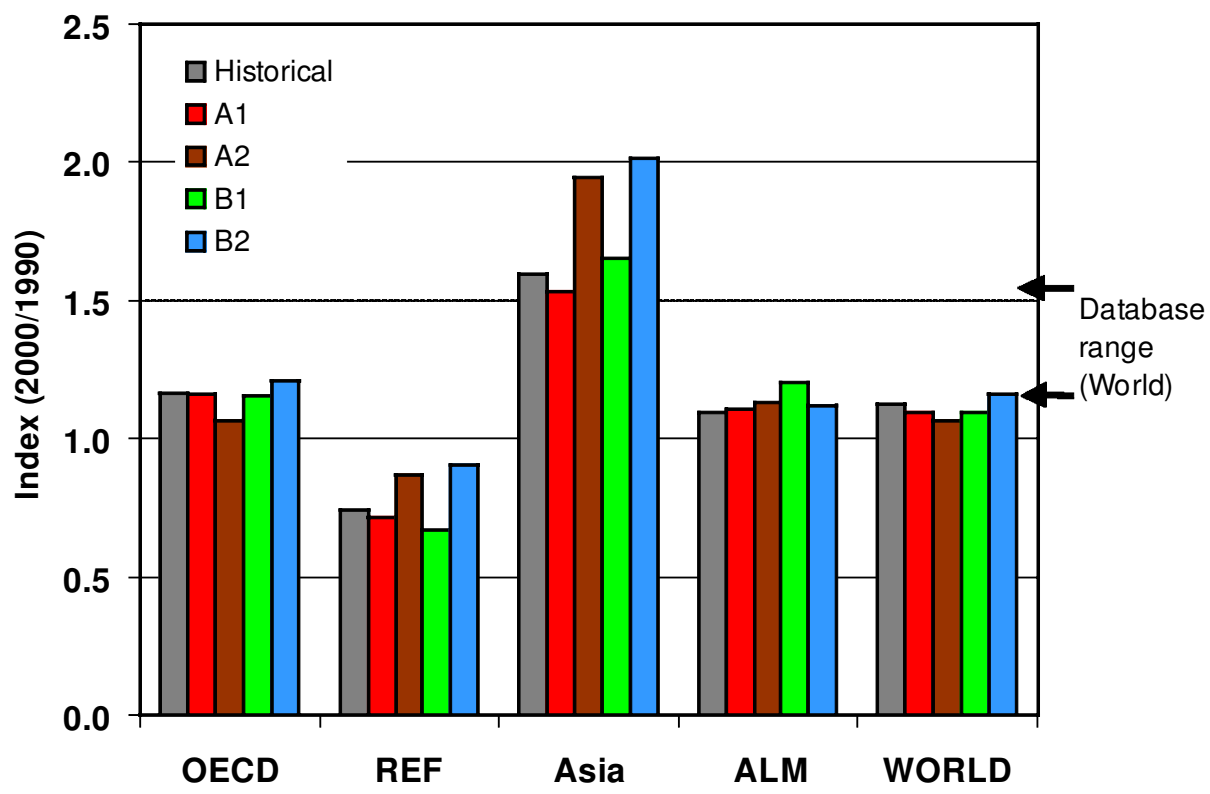

Figure 3a. 1990 to 2000 GDP MER per capita increase, shown as an index, in SRES marker scenarios for the world and the four SRES regions compared to actual historical development. Database range: database of scenarios published in the literature as reported in SRES (2000).

Sources: After van Vuuren (2003), SRES (2000), World Bank (2003b). 
that time. Thus, the actual developments through 2000 were obviously not known at that time. The six models were calibrated for base-year 1990 but with some differences across models due to statistical and other uncertainties. For this reason and other statistical discrepancies it is useful to compare GDP growth as an index across the scenarios and with the historical development. Figure 3a shows the 1990 to 2000 GDP per capita increase in SRES measured in MER and Figure $3 b$ in PPP for the world and the four SRES regions and compares this with the actual historical development. The differences across scenarios are relatively small so that SRES scenarios reflect historical changes well. The only real exceptions are the somewhat higher growth in the $\mathrm{B} 2$ and $\mathrm{A} 2$ scenarios for the REF and ASIA regions and somewhat lower growth in $\mathrm{A} 2$ for the OECD region.

It should be mentioned that SRES scenarios were not developed for the purpose of "projecting" the actual short-term developments. Their main objective was to cover the ranges of main driving forces and emissions in the literature with six different integrated modelling frameworks over a century time scale. It is an added bonus that they turned out to be quite robust in foreshadowing actual short-term historical development. This is a tribute to the enormous efforts that went into calibration of the base year in the six models and the short-term dynamics such as the capital vintage structures.

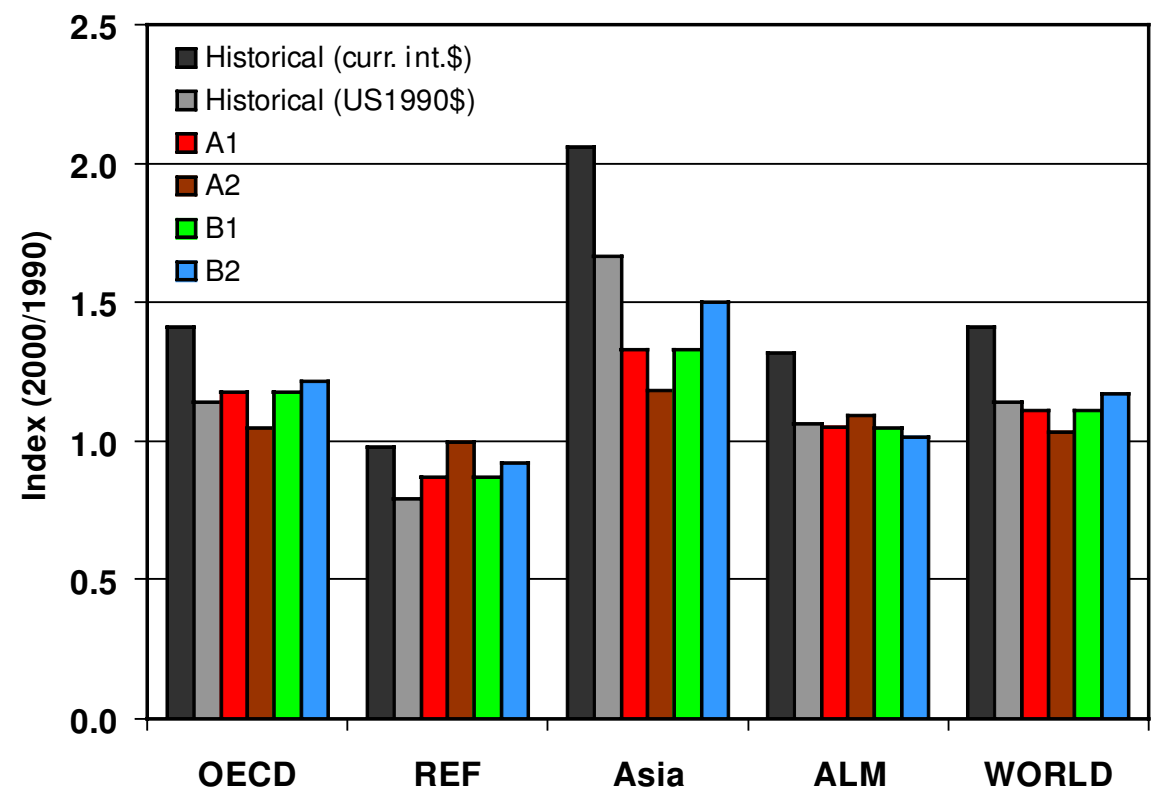

Figure 3b. 1990 to 2000 GDP PPP per capita increase, shown as an index, in SRES MESSAGE scenarios for the world and the four SRES regions compared to actual historical development, using current PPP in Dollars and PPP in terms of constant 1990 US Dollars.

Sources: After van Vuuren (2003), SRES (2000), World Bank (2003b). 


\section{SRES AND ECONOMIC DEVELOPMENT IN RECENT SCENARIOS}

We assess here the per capita economic development assumed in the three recent sets of economic scenarios by the World Bank (2003a), the USDoE (2002) and IEA (2002a) and compare them with the SRES scenarios. Figure 4 shows this comparison. SRES scenarios are again within the range of these more recent studies. They are bracketed by the two USDoE (2002) high and low scenarios. The USDoE reference scenario, the World Bank single scenario, and the IEA's single scenario are all right in the middle of the SRES range, between B2 and B1 development paths. This again confirms the "soundness" of the SRES range of economic growth. Table 2 shows the SRES medium-term growth rates of GDP in comparison with the three USDoE and World Bank scenarios, indicating again that the SRES range is within these more recent and shorter-term scenarios.

As mentioned above, all of these three studies give GDP in terms of MER. The SRES MER values were also used for this comparison. Thus, the claim by Mr. Castles that the methodology is flawed and "unsound" behind the SRES scenarios must apply to an even greater extent to the other studies since they give only MER, assuming of course, that the arguments he asserts are relevant and carry some weight. We do not believe that he has demonstrated a viable case in the face of the evidence given in these paragraphs that describe the recent scenarios literature.

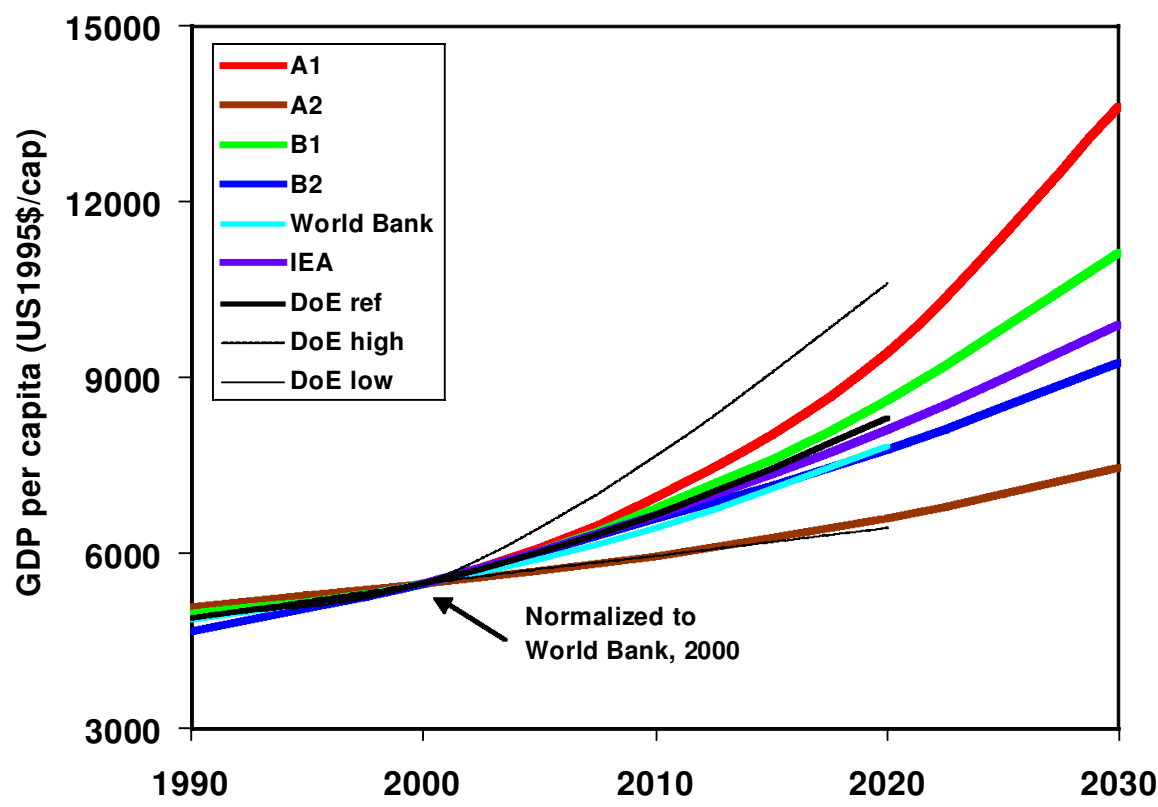

Figure 4. Comparison of GDP (MER) per capita of the SRES marker scenarios and the more recent studies by USDoE, World Bank and IEA.

Sources: After van Vuuren (2003), data sources: SRES (2000), World Bank (2003b), USDoE (2002) and IEA (2002). 
Table 3 also clearly indicates that in comparison with the few studies available that provide GDP scenarios in terms of $\mathrm{PPPs}^{8}$, the SRES scenarios are within the range and certainly not above comparable scenario studies when it comes to the GDP growth for developing countries.

Table 3 compares the short-term (1990 to 2000) PPP growth as described by the SRES scenarios (based on the MESSAGE model quantifications) with the estimates of actual growth over the period 1990 to 2001 as reported in Maddison (2002), as well as all PPP scenarios available in the literature for the period 1990-2020. Beyond the

Table 2. SRES medium-term GDP MER growth rates to 2020 in comparison with the three USDoE International Energy Outlook (IEO) scenarios and the latest World Bank scenario to 2015

\begin{tabular}{lccc} 
& SRES Marker & SRES Range & USDoE IEO 2002 \\
A1 & 7.4 & $5.9-7.4$ & 6.8 \\
A2 & 4.2 & $3.0-4.7$ & 3.4 \\
B1 & 6.0 & $5.3-6.0$ & - \\
B2 & 4.8 & $4.5-6.3$ & 5.0 \\
World Bank 2003* & 4.4 & & \\
\hline
\end{tabular}

* Projection to 2015

Sources: SRES (2000), World Bank (2003a), USDoE (2002).

Table 3. Comparison of medium-term scenarios that express GDP growth in PPP 1990-2000 1990-2020

World

SRES (2000)

$2.0-3.1$

$2.3-3.3$

WEC EfTW (1993)

n.a.

$3.3-3.8$

IIASA-WEC (1998)

n.a.

$2.2-2.7$

GSG (2002) ${ }^{(1)}$

n.a.

Maddison (2002) ${ }^{(2)}$

2.9

$2.7-3.1$

3.1

\section{Developing Countries}

SRES (2000)

WEC EfTW (1993)

IIASA-WEC (1998)

GSG (2002) ${ }^{(1)}$

Maddison (2002) (2)

(1) growth rates for period 1995-2025

(2) growth rates for period 1990-2015

Sources: WEC (1993), Nakicenovic et al. (1998), SRES (2000), Raskin et al. (2002), Kemp-Benedict et al. (2002) and Maddison (2002)

8 As a rule these studies provide PPP scenarios only for much shorter time horizons than the SRES scenarios, this being the reason why only medium-term growth rates up to 2020 can be compared in Table 3 . 
2020 period there are too few alternative scenarios available to enable a meaningful comparison. Table 3 lists the scenario studies reviewed and shows the time period for which the given average, compound growth rates are calculated. The studies include: SRES (2000, including four scenarios for 1990 to 2020 and to 2100); World Energy Council, Energy for Tomorrow's World (WEC, 1993, including 3 scenarios for 1990 to 2020); IIASA-WEC: Global Energy Perspectives (Nakicenovic et al., 1998, including 3 scenarios for 1990 to 2020 and to 2100); GSG: Global Scenario Group (Raskin et al., 2002, and Kemp-Benedict et al., 2002, including 4 scenarios for 1995 to 2025 and to 2050); and Angus Maddison's (2002) single scenario for the period 1990 to 2015.

\section{SRES AND $\mathrm{CO}_{2}$ EMISSIONS DURING THE LAST DECADE}

Mr. Castles (document in this issue 3(1):5) criticizes that the standardized ${ }^{9} \mathrm{CO}_{2}$ emissions for the year 2000 significantly overstate the actual emission growth over the period 1990 to 2000. In this context it is useful to recall that both past and current emission estimates are affected by inevitable degrees of uncertainty and therefore not precisely known, which requires considering more than just a single reference before arriving at the definitive conclusion. The SRES report reviews the relevant literature which gives a range between 6.0 to $8.2 \mathrm{GtC}$ for total $\mathrm{CO}_{2}$ emissions in the year 1990 (compared to a standardized value of $7.1 \mathrm{GtC}$ retained for the SRES scenarios) and a

\section{Table 4: 1990 and 2000 industrial $\mathrm{CO}_{2}$ emissions, a comparison of estimates (in MtC)}

\begin{tabular}{lcccr} 
& & & \multicolumn{2}{c}{ Increase } \\
& $\mathbf{1 9 9 0}$ & $\mathbf{2 0 0 0}$ & in MtC & in \% \\
SRES (standardized) & 5999 & 6896 & 897 & 15.0 \\
IEA, w/o cement & 5651 & 6338 & 737 & 13.0 \\
DOE, w/o cement & 5928 & 6468 & 540 & 9.1 \\
IEA, incl. cement & 5815 & 6623 & 808 & 13.9 \\
DoE, incl. cement & 6092 & 6703 & 611 & 10.0 \\
CDIAC ${ }^{(1)}$ & 6103 & 6457 & 354 & 5.8 \\
\hline
\end{tabular}

(1) 1999 data

Data sources: SRES (2000), IEA (2002b)

DOE: http://www.eia.doe.gov/emeu/international/environm.html

CDIAC: http://cdiac.ornl.gov/tp/ndp030/global99.ems

9 Because of the use of six different models with different base year calibrations, emissions of direct and indirect GHG emissions are standardized for the years 1990 and 2000 for all SRES scenarios, i.e. all scenarios share the same 1990 and 2000 emission values, emissions diverge thereafter reflecting scenario differences and thus uncertainty in the future. $\mathrm{CO}_{2}$ emissions were standardized separately for land-use change related emissions as well as for industrial emissions, which include emissions from the burning of fossil fuels, flaring of natural gas as well as the manufacture of cement. 
range of 5.0 to $6.0 \mathrm{GtC}$ for industrial sources of $\mathrm{CO}_{2}$ emissions (fossil fuel burning, flaring of natural gas and cement manufacture), to be compared with a standardized value of $6 \mathrm{GtC}$ retained for the SRES scenarios. As there are no recent estimates of land-use change related $\mathrm{CO}_{2}$ emissions available, our comparison focuses on industrial sources (fossil fuel plus cement manufacture).

A comparison of 1990 and 2000 industrial $\mathrm{CO}_{2}$ emissions is given in Table 4.

Two observations can be made. First, uncertainties evidently prevail for both past and current emission estimates and the SRES numbers are well within the literature range for the year 1990. Second, the standardized SRES emission estimate for the year 2000 (which was estimated in 1998) is evidently higher than any other currently available global emissions inventory, even when these are appropriately adjusted if they exclude the manufacturing of cement. ${ }^{10}$ Depending on the inventory used for the comparison, the SRES overestimation (15 percent growth) can be considered as acceptable (considering that we deal here with a forecast in the traditional sense of the word), e.g., when compared to the IEA inventory including cement manufacture (indicating a 14 percent growth), or as significant when compared to the CDIAC numbers for the year 1999, which indicate only a 6 percent growth. Mr. Castles has obviously cited the one inventory in which the discrepancy to the SRES numbers is the largest, without acknowledging the uncertainties that are inevitably involved in estimating global emissions inventories. One wonders if this is again an oversight, or again an example of selective quotation.

We complete our analysis by comparing the SRES scenarios for the 1990 to 2000 industrial $\mathrm{CO}_{2}$ emissions at the regional level, as shown in Figure $5^{11}$. The biggest overestimation of $\mathrm{CO}_{2}$ emissions occurs in the ASIA region and to a lesser extent in the reforming economies. Readers can judge for themselves about the acceptability of the corresponding margins of error. As an illustration of the state of knowledge available at the time the SRES scenarios were developed, the figure illustrates equally the range of projected global $\mathrm{CO}_{2}$ emission growth over the period 1990 to 2000 derived from the SRES data base of all published scenarios available in the literature.

\section{WOULD LOWER ECONOMIC GROWTH IN DEVELOPING COUNTRIES REDUCE GHG EMISSIONS?}

We raise this issue for a simple reason: first it is a recurrent inference suggested in the comments of Mr. Castles (see, e.g., his critique on the B1T MESSAGE scenario, document in this issue 3(2):9) that by lowering the GDP growth rate assumptions for the developing countries (but keeping all other scenario variables unchanged), the result would be (yet) lower emissions than reported in SRES, which allegedly have

10 Both the USDOE and the IEA $\mathrm{CO}_{2}$ emissions inventory exclude the manufacturing of cement. In the table therefore we give both the original figures from USDOE and the IEA as well as present our adjustments for including cement. Global cement production figures are derived from the USGS (1994 and 2001) which give a value of 1.16 and 1.66 billion metric tons for the years 1990 and 2000, respectively. Using the standard emission factor of $0.1413 \mathrm{tC} / \mathrm{t}$, this yields carbon emissions of 164 and $235 \mathrm{MtC}$ respectively for the two years, an increase of $71 \mathrm{MtC}$, or 43 percent.

11 CDIAC regional emission inventories for the year 1999 were unavailable to the authors at the time of writing this rebuttal. 
"exaggerated" potential future emission growth. This conjecture by Mr. Castles is incorrect both theoretically and practically.

The reason why such an argument is incorrect theoretically is (quite ironically) given by Mr. Henderson's discussion of the IPAT identity ${ }^{12}$, in which he contradicts his fellow critic, by arguing correctly that the income and technology variables in the IPAT identity are highly interdependent. This is simply because both the resources necessary for the generation of new technological knowledge (typically R\&D), as well as the resources required to apply new technological knowledge, are highly dependent on income levels. With no or low economic growth both R\&D expenditures, as well as capital turnover rates, are limited, which explains that in theory and practice technological change is ceteris paribus closely linked with income growth, or more precisely with the aggregate rate of macroeconomic productivity growth, usually represented by the growth of per capita GDP.

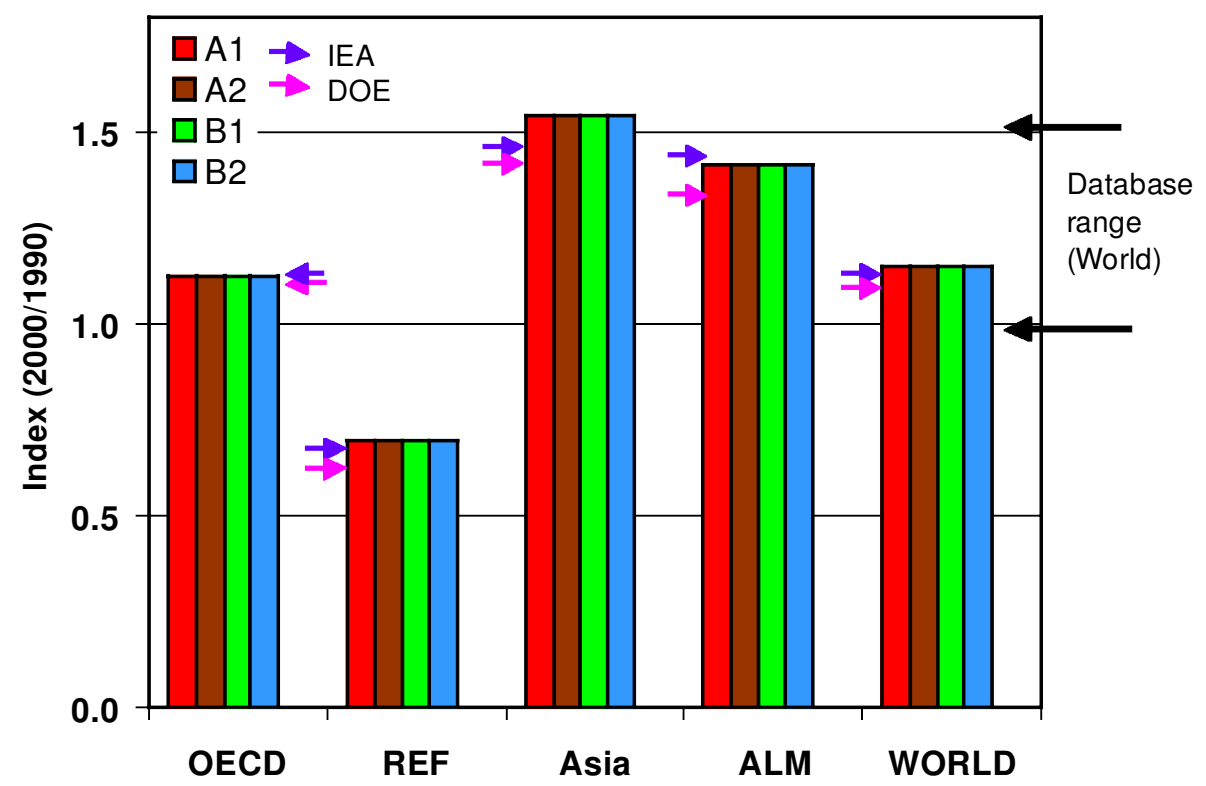

Figure 5. Growth in industrial $\mathrm{CO}_{2}$ emissions over the period 1990 to 2000, a comparison of SRES to recent inventory data of DOE and IEA, growth index 2000/1990. Data source: See text.

12 Contrary to Mr. Henderson's assertion, the SRES report discusses the IPAT identity not for giving it "a respectful airing" (document 3(2):8 in this issue), but simply because there is a wide body of literature that discusses the driving forces of future GHG emissions, a review of which constitutes part of the terms of reference for the SRES report. In fact the report is quite explicit in its critique of simplistic IPAT models due to the reasons of variable interdependence and spatial heterogeneity (cf. SRES, 2000:105-107). The issue of variable interdependence is also reviewed in detail in a separate subchapter on variable relationships, cf. SRES, 2000:119-125. 
The assumption that by lowering the GDP growth of developing countries (but not any other scenario variables) global GHG emissions would be lower is also incorrect with respect to the models used to derive long-term GHG emissions scenarios. First, models in which both the rate of macroeconomic productivity growth and the rate of technological change are exogenous variables, require a set of consistent input assumptions. Scenario variables can therefore not be chosen arbitrarily, e.g., in combining assumptions on a stagnating economy in developing countries with bullish assumptions on the development and adoption of advanced (and expensive) low emissions technologies such as fuel cells or hydrogen infrastructures also in developing countries (a necessary condition for any long-term low emission scenario). In addition, many models used for the development of the SRES scenarios incorporate a number of endogenous technological change features, most notably a detailed representation of the capital vintage structure of an economy. With low economic growth, this vintage structure turns over quite slowly, and a rapid diffusion of new technologies would be possible only via an expensive, premature retirement of the capital stock, the costs of which are especially prohibitive in scenarios of low economic growth. Assuming rapid technological change in the absence of rapid capital turnover rates would therefore possibly be inconsistent with the terms of reference of the SRES scenarios of not considering additional climate policies beyond those that were in place in 1996.

The result of lowering GDP growth assumptions in the developing countries in the more optimistic scenario families A1 and B1 would therefore not change anything in the projected emission range of the SRES scenarios. If anything, emissions would tend to move in the direction of the low growth, slower technology scenario family A2, i.e. be higher rather than lower as conjectured by Mr. Castles.

Thus, there remains substantial agreement - even if for reasons other than conjectured by Mr. Castles and Mr. Henderson. The "questionable presumption" (document 3(2):8 in this issue) that the variables of the IPAT identity, in particular between growth in incomes and technology, can be treated as independent from each other (as suggested by Mr. Castles) is in fact no "presumption" at all. The SRES report (and its authors) are very explicit in stating that the variables are indeed interdependent and this is amply reflected in the SRES scenarios. We also agree with Mr. Castles that the emissions (in terms of radiative forcing) of the lowest SRES scenario B1TMESSAGE do not constitute a lower bound of future GHG emissions (document $3(1): 4$ in this issue). But the reason for this is not that the GDP growth in developing countries is "too high", but rather because the scenario does not assume any climate policies aimed at reducing GHG emissions. If the purpose of Mr. Castles and Mr. Henderson is to avoid climate policies aimed at reducing GHG emissions then theirs would be a legitimate position. What is not legitimate is to construct the case in a misleading way against the SRES scenarios.

\section{CONCLUSIONS}

We concur with Mr. Castles and Mr. Henderson that emissions scenarios need to be evaluated and revised as new knowledge emerges. It is an ongoing process that in some sense started before the SRES scenarios were completed and which at some 
point in the future will require the development of a new set of emissions scenarios to replace SRES. The IPCC meeting in Amsterdam, 8-10 January 2003 was a step in this direction, focusing specifically on the future use of scenarios in the IPCC. The modelling community is continuously developing new scenarios and the literature on scenario development has increased since the publication of SRES. It is significant, however, that many of the new scenarios are based on SRES.

We strongly disagree with the assertions by Mr. Castles and Mr. Henderson that the scenarios are "technically unsound" and methodologically flawed. We have shown that the main criticism that scenarios must be based on PPP is completely unfounded and misplaced. We have further refuted their assertions that economic development in SRES scenarios is based only on MER as the scenarios equally include PPP.

Their criticism that growth rates in developing countries are absurdly too high is not on solid ground either. First, the set of scenarios A2 leaves the income gap (measured at PPP) between developed and developing regions unclosed in relative terms (at about four to one). In absolute terms, the income gap grows in all scenarios. Even the set of scenarios with the highest growth rates A1 falls within the range of historical experience and is consistent both with recent developments from 1990 to 2000 and with scenarios developed since publication of SRES.

Finally, the strong words they use to describe the absurd nature of scenarios for some individual countries are to an extent warranted. But these country-related scenarios are not part of SRES. They are based on work in progress that has not even been published yet. To attribute to SRES these preliminary attempts to downscale global scenarios to national levels is a deplorable misinformation. The six SRES integrated modelling frameworks do not have the degree of spatial resolution required for developing country level scenarios and this is the reason why all SRES findings are reported for four world regions only.

Mr. Castles and Mr. Henderson have focused (at tedious length) on constructing a "problem" that does not exist. IPCC as an institution is responding seriously and conscientiously. The accusations of "non-response" are simply unfounded as both gentlemen participated in the IPCC meeting, 8-10 January 2003, in Amsterdam and had both extensive discussions with members of the SRES writing team and ample opportunities to present their case. However, IPCC is not a debating society. It is an assessment body. It does not normally produce responses to individual researchers outside the context of a document review process, or, except out of courtesy when member governments have requested special attention for a particular issue or comment. This courtesy has been more than extended in this case. We will continue to look at the question of PPP, as suggested by Mr. Castles and Mr. Henderson, perhaps jointly with other organizations such as the OECD. SRES provides an excellent basis for this assessment as it is one of the very few studies that describes economic development also in terms of PPP. We will continue to improve the scenarios in other ways as well. But we do not want to lose sight in these considerations of even more important issues, e.g., technology change, that have a far greater impact on future emissions than does the choice of economic metric. 


\section{REFERENCES}

Alcamo, J., A. Bouwman, J. Edmonds, A. Grübler, T. Morita, and Sugandhy, A., 1995: An evaluation of the IPCC IS92 emission scenarios. In Climate Change 1994, Radiative Forcing of Climate Change and An Evaluation of the IPCC IS92 Emission Scenarios, Cambridge University Press, Cambridge, pp. 233-304.

Alcamo, J. and Nakicenovic, N., (eds.), 1998: Long-term Greenhouse Gas Emission Scenarios and Their Driving Forces, Mitigation and Adaptation Strategies for Global Change 3, Nos. 2-4. Kluwer Academic Publishers, Dordrecht.

Carbon Dioxide Information Analysis Center (CDIAC), G. Marland, T. Boden, and Andres, R.J., 2002: Global $\mathrm{CO}_{2}$ Emissions from Fossil-Fuel Burning, Cement Manufacture, and Gas Flaring: 1751-1999. http://cdiac.ornl.govftp/ndp030/global99.ems

de la Escousura, L.P., 2000: International Comparisons of Real Product, 1820-1990: An Alternative Data Set, Explorations in Economic History, 37, 1-41.

International Energy Agency (IEA), 2002a: World Energy Outlook 2002. OECD/IEA, Paris.

International Energy Agency (IEA), 2002b: $\mathrm{CO}_{2}$ Emissions from Fossil Fuel Combustion 1971-2000, 2002 Edition. IEA, Paris.

IPCC Special Report on Emissions Scenarios (SRES), Nakicenovic, N., Alcamo, J., Davis, G., de Vries, B., Fenhann, J., Gaffin, S., Gregory, K., Grübler, A. et al., 2000: Special Report on Emissions Scenarios, Working Group III, Intergovernmental Panel on Climate Change (IPCC), Cambridge University Press, Cambridge, 595 pp. http://www.grida.no/climate/ipcc/emission/ index.htm

Kausel, A. (ed), 1985: 150 Years of Economic Growth in Austria and the Western World as Reflected in Statistics. Verlag der Österreichischen Staatsdruckerei, Vienna (in German).

Kemp-Benedict, E., Heaps, C., and Raskin, P., 2002: Global scenario group futures, technical notes, 2002, Stockholm Environment Institute, Stockholm.

Kravis, I.B., A. Heston, and Summers, R., 1978: International comparisons of real product and purchasing power, Published for the World Bank, The Johns Hopkins University Press, Baltimore and London.

Leggett, J., W.J. Pepper, and Swart, R., 1992: Emissions scenarios for IPCC: An update. In Climate Change 1992. Supplementary Report to the IPCC Scientific Assessment, J.T. Houghton, B.A. Callander, S.K.Varney (eds.), Cambridge University Press, Cambridge, pp. 69-95 .

Maddison, A., 2001: The World Economy, a Millennial Perspective. OECD Development Centre, OECD, Paris.

Maddison, A., 2002: The west and the rest in the international economic order. In Braga de Macedo et al. (eds.), Development is Back, OECD Development Centre, Paris, pp. 31-46.

Metz, B., Davidson, O., Swart, R., and Pan, J.,(eds), 2001: Climate Change 2001: Mitigation. Cambridge University Press.

Nakicenovic, N., (ed.), 2000: Greenhouse gas emissions scenarios. Technological Forecasting \& Social Change, 65,3. 
Nakicenovic, N., Grübler, A., and McDonald, A. (eds.), 1998: Global Energy Perspectives, Cambridge University Press.

Nakicenovic, N., Victor, N., and Morita, T., 1998: Emissions scenarios database and review of scenarios. Mitigation and Adaptation Strategies for Global Change, 3, 2-4, 95-131.

Nordhaus, W.D., and Boyer, J., 2000: Warming the World, Economic Models of Global Warming, The MIT Press, Cambridge.

Raskin, P., Banuri, T., Gallopin, G., Gutman, P., Hammond, A., Kates, R., Swart, R., 2002: Great Transition: The Promise and Lure of the Times Ahead, Global Scenario Group, Stockholm Environment Institute, Stockholm.

US Department of Energy (USDoE), 2002: International Energy Outlook 2002. DOE/EIA0484, Washington D.C.

US Department of Energy (USDoE), 2003: International Energy-related Environmental Information. http://www.eia.doe.gov/emeu/international/environm.html

US Geological Survey (USGS), 1994: Minerals Yearbook. Commodity Summary: Cement (C. Solomon). USGS, Washington D.C. http://minerals.usgs.gov/minerals/pubs/commodity/ cement/170494.pdf

US Geological Survey (USGS), 2001: Minerals Yearbook. Commodity Summary: Cement (H.G. van Oss). USGS, Washington D.C. http://minerals.usgs.gov/minerals/pubs/commodity/ cement/cememyb01.pdf

Voeller, J., 1981: Mathematical systems in economics, 72, Purchasing Power Parities for International Comparisons, Oeigeschlarger, Gunn \& Hain, Meisenheim/Glan.

Van Vuuren, D.P., 2003: SRES vs. Historic Trends and Near Term Projections. Presentation at TGCIA, 10 January, 2003, Amsterdam.

World Energy Council (WEC), 1993: Energy for Tomorrow's World, Kogan Page, St. Martin's Press, London.

World Bank, 2003a: Global economic prospects and the developing countries 2003. World Bank, Washington D.C. http://www.worldbank.org/prospects/gep2003/

World Bank, 2003b: World development indicators. World Bank, Washington D.C. http://www.worldbank.org 


\title{
APPENDIX
}

Table A-1. GDP per capita 1000 US\$(1990) from the SRES scenarios calculated with the MESSAGE model that is calibrated both with MER and PPP

\author{
$\begin{array}{llllllllllll}1990 & 2000 & 2010 & 2020 & 2030 & 2040 & 2050 & 2060 & 2070 & 2080 & 2090 & 2100\end{array}$
}

A1

$\begin{array}{llrrrrrrrrrrrr}\text { World } & \text { mer } & 4.0 & 4.4 & 5.5 & 7.4 & 10.9 & 15.8 & 20.8 & 28.6 & 37.1 & 47.2 & 59.5 & 74.9 \\ & \text { ppp } & 4.9 & 5.4 & 6.8 & 8.7 & 11.8 & 16.3 & 20.8 & 27.8 & 35.9 & 45.8 & 57.9 & 72.8 \\ \text { OECD90 } & \text { mer } & 19.1 & 22.3 & 26.2 & 30.8 & 36.5 & 43.1 & 50.1 & 60.5 & 70.6 & 82.3 & 95.4 & 109.1 \\ & \text { ppp } & 16.4 & 19.3 & 22.6 & 26.7 & 31.7 & 37.5 & 43.7 & 52.8 & 61.8 & 72.1 & 83.8 & 96.0 \\ \text { REF } & \text { mer } & 2.7 & 2.0 & 3.6 & 6.6 & 12.2 & 20.4 & 29.3 & 39.6 & 51.1 & 65.2 & 82.0 & 100.8 \\ & \text { ppp } & 6.2 & 5.4 & 7.3 & 10.0 & 13.7 & 20.4 & 29.3 & 39.6 & 51.1 & 65.2 & 82.0 & 100.8 \\ \text { ASIA } & \text { mer } & 0.5 & 0.8 & 1.6 & 3.1 & 6.3 & 10.5 & 14.9 & 22.5 & 31.3 & 41.8 & 54.8 & 71.9 \\ & \text { ppp } & 1.9 & 2.5 & 3.7 & 5.5 & 8.5 & 12.2 & 16.0 & 22.8 & 31.3 & 41.8 & 54.8 & 71.9 \\ \text { ALM } & \text { mer } & 1.6 & 1.8 & 2.8 & 4.6 & 7.6 & 12.8 & 17.5 & 23.9 & 30.8 & 38.7 & 48.5 & 60.8 \\ & \text { ppp } & 3.2 & 3.4 & 4.6 & 6.1 & 8.8 & 13.7 & 18.1 & 23.9 & 30.8 & 38.7 & 48.5 & 60.8\end{array}$

A2

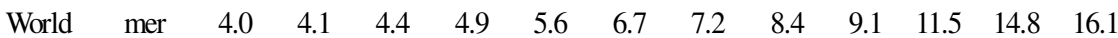
$\begin{array}{lllllllllllll}\text { ppp } & 4.9 & 5.1 & 5.5 & 6.2 & 6.9 & 7.7 & 9.4 & 10.9 & 12.3 & 13.0 & 14.1 & 15.0\end{array}$

$\begin{array}{llllllllllllll}\text { OECD90 } & \text { mer } & 18.0 & 20.3 & 22.9 & 25.3 & 28.0 & 32.9 & 34.6 & 38.6 & 40.7 & 47.7 & 55.6 & 58.5\end{array}$ $\begin{array}{llllllllllllll}\text { ppp } & 16.5 & 17.3 & 19.0 & 20.2 & 21.6 & 25.0 & 26.7 & 30.1 & 31.7 & 37.5 & 44.0 & 46.7\end{array}$

$\begin{array}{llllllllllllll}\text { REF } & \text { mer } & 2.3 & 1.9 & 2.4 & 3.1 & 4.4 & 6.3 & 7.1 & 8.9 & 10.0 & 13.7 & 18.3 & 20.2\end{array}$ $\begin{array}{lllllllllllll}\text { ppp } & 6.1 & 6.1 & 7.4 & 9.3 & 10.6 & 12.3 & 17.4 & 19.8 & 22.8 & 20.1 & 18.6 & 19.5\end{array}$

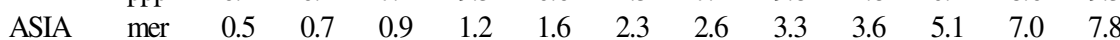
$\begin{array}{lllllllllllll}\text { ppp } & 1.9 & 2.3 & 2.7 & 3.3 & 4.1 & 5.0 & 6.4 & 7.7 & 9.0 & 9.6 & 10.3 & 10.9\end{array}$

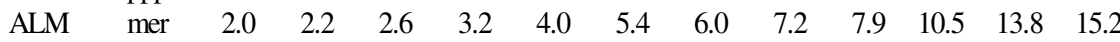
$\begin{array}{lllllllllllll}\text { ppp } & 3.1 & 3.4 & 3.9 & 4.6 & 5.5 & 5.7 & 7.6 & 8.8 & 10.3 & 10.3 & 10.5 & 11.3\end{array}$

B1

$\begin{array}{llllllllllllll}\text { World } & \text { mer } & 4.0 & 4.4 & 5.3 & 6.8 & 8.9 & 11.8 & 15.6 & 19.8 & 24.6 & 30.7 & 37.9 & 46.5\end{array}$ $\begin{array}{lllllllllllll}\text { ppp } & 4.9 & 5.4 & 6.5 & 8.1 & 10.0 & 12.7 & 16.1 & 19.8 & 24.1 & 29.8 & 36.7 & 45.2\end{array}$

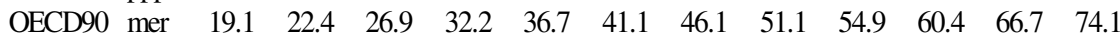
$\begin{array}{lllllllllllll}\text { ppp } & 16.4 & 19.3 & 23.3 & 27.9 & 31.9 & 35.8 & 40.3 & 44.7 & 48.2 & 53.2 & 58.8 & 65.5\end{array}$

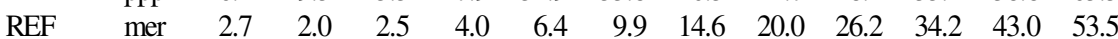
$\begin{array}{lllllllllllll}\text { ppp } & 6.2 & 5.4 & 6.0 & 7.7 & 9.8 & 12.3 & 15.1 & 20.0 & 26.2 & 34.2 & 43.0 & 53.5\end{array}$

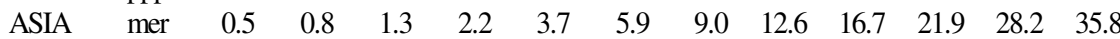
$\begin{array}{lllllllllllll}\text { ppp } & 1.9 & 2.5 & 3.3 & 4.4 & 5.9 & 8.1 & 10.9 & 14.0 & 17.5 & 22.1 & 28.2 & 35.8\end{array}$ $\begin{array}{llllllllllllll}\text { ALM } & \text { mer } & 1.6 & 1.7 & 2.3 & 4.2 & 6.6 & 9.9 & 14.0 & 18.4 & 23.6 & 30.0 & 37.2 & 45.8\end{array}$ $\begin{array}{lllllllllllll}\text { ppp } & 3.2 & 3.4 & 4.0 & 5.7 & 7.9 & 11.0 & 14.8 & 18.7 & 23.6 & 30.0 & 37.2 & 45.8\end{array}$

B2

$\begin{array}{llllllllllllll}\text { World } & \text { mer } & 4.0 & 4.6 & 5.6 & 6.6 & 7.9 & 9.6 & 11.7 & 13.9 & 16.2 & 18.3 & 20.4 & 22.6\end{array}$ $\begin{array}{llllllllllllll}\text { ppp } & 4.9 & 5.7 & 6.8 & 7.8 & 9.0 & 10.4 & 12.2 & 14.1 & 16.1 & 18.1 & 20.1 & 22.3\end{array}$ $\begin{array}{llllllllllllll}\text { OECD90 } & \text { mer } & 19.1 & 23.0 & 27.8 & 30.9 & 33.3 & 36.2 & 39.2 & 42.4 & 46.7 & 50.9 & 55.7 & 61.0\end{array}$ $\begin{array}{lllllllllllll}\text { ppp } & 16.4 & 19.9 & 24.1 & 26.8 & 29.0 & 31.6 & 34.4 & 37.2 & 41.2 & 45.1 & 49.4 & 54.3\end{array}$ $\begin{array}{llllllllllllll}\text { REF } & \text { mer } & 2.7 & 2.4 & 2.9 & 4.3 & 6.7 & 10.9 & 16.3 & 21.7 & 27.0 & 31.0 & 34.6 & 38.3\end{array}$ $\begin{array}{lllllllllllll}\text { ppp } & 6.2 & 5.7 & 6.4 & 7.9 & 10.4 & 13.7 & 17.7 & 24.1 & 29.8 & 34.7 & 38.8 & 42.7\end{array}$

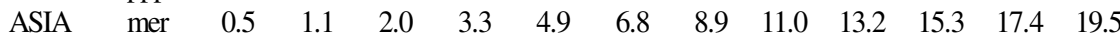
$\begin{array}{lllllllllllll}\text { ppp } & 1.9 & 2.9 & 4.1 & 5.6 & 7.1 & 8.7 & 10.5 & 12.3 & 14.2 & 16.0 & 18.1 & 20.2\end{array}$ $\begin{array}{llllllllllllll}\text { ALM } & \text { mer } & 1.6 & 1.8 & 2.0 & 2.4 & 3.3 & 4.9 & 6.9 & 9.2 & 11.3 & 13.1 & 14.6 & 16.1\end{array}$ $\begin{array}{lllllllllllll}\text { ppp } & 3.2 & 3.3 & 3.3 & 3.6 & 4.4 & 5.7 & 7.3 & 9.1 & 11.0 & 12.6 & 14.1 & 15.7\end{array}$ 
Table A-2. GDP per capita growth rates (from 1990) from the SRES scenarios calculated with the MESSAGE model that is calibrated both with MER and PPP

$\begin{array}{llllllllllll}1990 & 2000 & 2010 & 2020 & 2030 & 2040 & 2050 & 2060 & 2070 & 2080 & 2090 & 2100\end{array}$

A1

World mer

$\begin{array}{lllllllllll}0.9 & 1.6 & 2.0 & 2.5 & 2.8 & 2.8 & 2.8 & 2.8 & 2.8 & 2.7 & 2.7\end{array}$

$\begin{array}{lllllllllll}1.0 & 1.6 & 1.9 & 2.2 & 2.4 & 2.4 & 2.5 & 2.5 & 2.5 & 2.5 & 2.5\end{array}$

OECD90 mer

$\begin{array}{lllllllllll}1.4 & 1.5 & 1.6 & 1.6 & 1.6 & 1.6 & 1.6 & 1.6 & 1.6 & 1.6 & 1.6\end{array}$

ppp

$\begin{array}{lllllllllll}1.5 & 1.6 & 1.6 & 1.6 & 1.6 & 1.6 & 1.7 & 1.7 & 1.6 & 1.6 & 1.6\end{array}$

REF mer

$\begin{array}{llll}-2.6 & 1.5 & 3.0 & 3.8\end{array}$

4.14 .0

$3.9 \quad 3.7$

$\begin{array}{llll}-1.3 & 0.8 & 1.6 & 2.0\end{array}$

$2.4 \quad 2.6$

$\begin{array}{lllll}2.7 & 2.6 & 2.6 & 2.6 & 2.5\end{array}$

ASIA mer

$\begin{array}{llll}4.1 & 5.3 & 5.9 & 6.2\end{array}$

$\begin{array}{lll}6.0 & 5.6 & 5.4\end{array}$

$\begin{array}{llll}2.6 & 3.3 & 3.5 & 3.7\end{array}$

3.7

$5.4 \quad 5.1$

$\begin{array}{llll}0.9 & 2.8 & 3.5 & 3.9\end{array}$

4.2

$3.6 \quad 3.6$

$0.5 \quad 1.7$

2.12 .5

2.9

$4.0 \quad 3.9$

$\begin{array}{ll}3.6 & 3.5 \\ 3.9 & 3.7\end{array}$

$\begin{array}{lll}4.9 & 4.7 & 4.5\end{array}$

ALM mer

A2

World mer

$\begin{array}{llll}0.3 & 0.5 & 0.7 & 0.8\end{array}$

2.9

$2.9 \quad 2.8$

\begin{tabular}{ll}
3.4 & 3.3 \\
\hline
\end{tabular}

$0.3 \quad 0.6$

$\begin{array}{ll}0.7 & 0.8\end{array}$

$1.0 \quad 1.0$

$1.1 \quad 1.0$

2.8

$3.4 \quad 3.3$

$\begin{array}{ll}1.1 & 1.1\end{array}$

1.1

0.9

$1.1 \quad 1.1$

$\begin{array}{llll}1.0 & 1.2 & 1.3 & 1.3\end{array}$

OECD90 mer

$\begin{array}{ll}0.4 & 0.7\end{array}$

$0.7 \quad 0.7$

1.2

1.1

1.1

1.1

$\begin{array}{lll}1.1 & 1.1 & 1.0\end{array}$

$-1.4 \quad 0.2$

$\begin{array}{lll}1.1 & 1.6 & 2.0\end{array}$

$\begin{array}{lll}0.8 & 0.8 & 0.8\end{array}$

$\begin{array}{lll}1.1 & 1.1 & 1.1\end{array}$

REF mer

$\begin{array}{llll}0.0 & 0.9 & 1.4 & 1.4\end{array}$

$\begin{array}{ll}2.7 & 2.8\end{array}$

$2.9 \quad 2.8$

2.0

$1.9 \quad 2.0$

0.8

$\begin{array}{lll}0.9 & 1.0 & 0.9\end{array}$

ASIA mer

$\begin{array}{llll}1.6 & 1.7 & 1.8 & 1.9\end{array}$

3.0

$1.7 \quad 1.7$

1.0

$\begin{array}{lll}2.0 & 2.1 & 2.0\end{array}$

1.21.

1.9

2.7

$2.6 \quad 2.4$

$\begin{array}{lll}1.3 & 1.1 & 1.1\end{array}$

ppp

$0.8 \quad 1$.

$.3 \quad 1.6$

$\begin{array}{lll}1.9 & 2.0 & 2.0\end{array}$

$2.0 \quad 1.9$

$\begin{array}{lll}2.5 & 2.6 & 2.5\end{array}$

ALM mer
ppp

B1

Ppp

World mer

$\begin{array}{llll}0.9 & 1.3 & 1.8 & 2.0\end{array}$

2.0
12

$1.8 \quad 1.9$

1.9

$\begin{array}{lll}1.8 & 1.7 & 1.6\end{array}$

ppp

$\begin{array}{llll}1.0 & 1.3 & 1.6 & 1.8\end{array}$

$\begin{array}{llll}1.5 & 1.6 & 1.7 & 1.6\end{array}$

2.2

$1.5 \quad 1.5$

1.7

$\begin{array}{lll}1.9 & 2.0 & 1.9\end{array}$

OECD90 mer

$\begin{array}{ll}1.5 & 1.7\end{array}$

$\begin{array}{ll}1.7 & 1.6\end{array}$

1.9

$2.3 \quad 2.3$

$2.3 \quad 2.3$

$\begin{array}{lll}1.3 & 1.2 & 1.2\end{array}$

REF mer

$-2.6-0.3$

$1.3 \quad 2.2$

$-1.3-0.1$

$0.7 \quad 1.1$

1.5

2.0

$2.0 \quad 2.0$

$\begin{array}{lll}2.3 & 2.3 & 2.2\end{array}$

$\begin{array}{ll}4.1 & 4.4\end{array}$

$\begin{array}{ll}4.7 \quad 4.8 \\ 2.7 & 2.8\end{array}$

2.6

$1.5 \quad 1.4$

2.0

$\begin{array}{lll}2.0 & 2.0 & 2.0\end{array}$

ASIA mer

$2.6 \quad 2.7$

$\begin{array}{ll}2.7 & 2.8 \\ 3.1 & 3.5\end{array}$

1.4

$1.5 \quad 1.4$

1.41 .3

$\begin{array}{lll}1.3 & 1.2 & 1.2\end{array}$

$0.8 \quad 1.9$

3.

4.8

2.8

2.92 .9

$\begin{array}{lll}1.3 & 1.3 & 1.3\end{array}$

$0.4 \quad 1.1$

1.9

B2

ppp

$\begin{array}{llll}1.4 & 1.7 & 1.7 & 1.7\end{array}$

$\begin{array}{llll}1.4 & 1.6 & 1.5 & 1.5\end{array}$

2.9

4.7

$\begin{array}{ll}1.7 & 1.8\end{array}$

$\begin{array}{lll}2.8 & 2.8 & 2.7\end{array}$

World mer

$\begin{array}{lll}1.7 & 1.8 & 1.6\end{array}$

2.9

$\begin{array}{ll}4.5 & 4.3\end{array}$

$\begin{array}{lll}1.9 & 1.9 & 2.0\end{array}$

$\begin{array}{rlll}1.8 & 1.9 & 1.6 & 1.4\end{array}$

2.9

$\begin{array}{lll}4.2 & 4.0 & 3.9\end{array}$

3.5

3.6
2.4

$3.6 \quad 3.5$

$\begin{array}{lll}2.7 & 2.7 & 2.7\end{array}$

3.53.

$\begin{array}{lll}3.3 & 3.2 & 3.1\end{array}$

$\begin{array}{llll}-0.9 & 0.4 & 1.6 & 2.3\end{array}$

$\begin{array}{llll}-0.7 & 0.1 & 0.8 & 1.3\end{array}$

1.7

$2.5 \quad 2.5$

2.5

$\begin{array}{lll}2.5 & 2.5 & 2.4\end{array}$

OECD90 mer

ppp

REF mer

$\begin{array}{llll}6.6 & 6.4 & 6.0 & 5.6\end{array}$

1.5

$1.8 \quad 1.8$

$1.8 \quad 1.8$

$1.8 \quad 1.7$

$1.7 \quad 1.6$

$1.6 \quad 1.6$

$\begin{array}{llll}3.8 & 3.8 & 3.5 & 3.3\end{array}$

$1.5 \quad 1.5$

$\begin{array}{lll}1.4 & 1.4 & 1.4\end{array}$

$1.4 \quad 1.3$

1.21 .1

$\begin{array}{llll}1.1 & 1.1 & 1.1 & 1.1\end{array}$

ppp

ASIA mer

$\begin{array}{llll}1.0 & 1.0 & 1.4 & 1.8\end{array}$

1.3

$1.2 \quad 1.2$

$\begin{array}{llll}1.1 & 1.1 & 1.1 & 1.1\end{array}$

$\begin{array}{llll}0.2 & 0.1 & 0.4 & 0.8\end{array}$

$\begin{array}{llll}2.8 & 3.0 & 3.0 & 2.9\end{array}$

$\begin{array}{lll}2.7 & 2.6 & 2.4\end{array}$

$\begin{array}{lllllll}1.6 & 1.7 & 1.9 & 2.0 & 1.9 & 1.8 & 1.8\end{array}$

$\begin{array}{lllllll}5.1 & 4.7 & 4.3 & 4.0 & 3.8 & 3.5 & 3.3\end{array}$

ALM mer

$\begin{array}{lll}3.0 & 2.8 & 2.7\end{array}$

$\begin{array}{lllll}2.7 & 2.5 & 2.4 & 2.3 & 2.2\end{array}$

.82 .2

2.4

$2.5 \quad 2.4$

$\begin{array}{lll}2.3 & 2.2 & 2.1\end{array}$

Source: (SRES, 2000) 